\title{
Arnold-Chiari Malformation Type III With Meningoencephalocele: A Case Report
}

\author{
Dae Ho Jeong, $\mathrm{MD}^{1}$, Chang Hwan Kim, $\mathrm{MD}^{1}$, Myeong Ok Kim, MD¹, Hyung Chung, MD¹, \\ Tae Hyun Kim, MS', Han Young Jung, MD $^{1}$ \\ ${ }^{1}$ Department of Physical and Rehabilitation Medicine, Inha University School of Medicine, Incheon; \\ ${ }^{2}$ Department of Physical and Rehabilitation Medicine, Inha University Hospital, Incheon, Korea
}

\begin{abstract}
Arnold-Chiari malformation type III (CM III) is an extremely rare anomaly with poor prognosis. An encephalocele with brain anomalies as seen in CM II, and herniation of posterior fossa contents like the cerebellum are found in CM III. The female infant was a twin, born at 33 weeks, weighing $1.7 \mathrm{~kg}$ with a huge hydrocele on the craniocervical junction. After operations were performed, she was referred to the department of rehabilitation medicine for poor motor development, swallowing dysfunction, and poor eye fixation at 22 months. The child was managed with neurodevelopmental treatment, oromotor facilitation, and light perception training. After 14 months, improvement of gross motor function was observed, including more stable head control, rolling, and improvement of visual perception. CM III has been known as a condition with poor prognosis. However, with the improvement in operative techniques and intensive rehabilitations, the prognosis is more promising than ever before. Therefore, more attention must be paid to the rehabilitation issues concerning patients with CM III.
\end{abstract}

Keywords Chiari III malformation, Developmental disabilities, Cortical blindness, Rehabilitation

\section{INTRODUCTION}

Arnold-Chiari malformation (CM) is a congenital hypoplastic disease of the hindbrain which is characterized by spinal cord abnormality and hydrocephalus, due to some part of cerebellar prolapse(s) into the spinal cavity through the occipital defect. It was first reported by Hans

Received June 25, 2013; Accepted August 21, 2013

Corresponding author: Han Young Jung

Department of Physical and Rehabilitation Medicine, Inha University School of Medicine, 27 Inhang-ro, Jung-gu, Incheon 400-711, Korea Tel: +82-32-890-2480, Fax: +82-32-890-2486, E-mail: rmjung@inha.ac.kr

(ㄷ) This is an open-access article distributed under the terms of the Creative Commons Attribution Non-Commercial License (http://creativecommons. org/licenses/by-nc/3.0) which permits unrestricted noncommercial use, distribution, and reproduction in any medium, provided the original work is properly cited.

Copyright $\odot 2014$ by Korean Academy of Rehabilitation Medicine
Chiari through the autopsy of 40 children with hindbrain dysplasia in 1981, and was classified into 4 types according to the degree of prolapse of the cerebellum [1]. Among them, CM I and II are relatively common, but CM III and IV are very rare. CM III is known to be accompanied by meningoencephalocele of the top of cervical vertebra and occipital region, cerebellar prolapse, and hydrocephalus [2]. Newborn infants with CM III often suffer from respiratory failure, swallowing dysfunction, hypertonia, or amyotonia. Due to significant respiratory failure associated with this type, the prognosis is known to be very poor [3]. As a result, it is difficult to find literature for rehabilitation management and features of the growth of infants with CM III.

In 2005, Cho et al. [4] made the first report of CM III in Korea; however, there have been no case reports on rehabilitation treatment for patients with CM III. Herein, we 
report the case of a child diagnosed as CM III accompanied by meningoencephalocele at birth. Improvements in motor function and visual perception response with good survival were achieved through the use of neurodevelopmental treatment, oromotor facilitation, visual stimulus treatment, and functional electrical stimulation. In addition, we provided the details of magnetic resonance imaging (MRI), swallowing status and rehabilitation treatment methods, including a literature review.

\section{CASE REPORT}

This female infant was born in the 33rd week of twin gestation (birth weight, $1.7 \mathrm{~kg}$ ) by cesarean section. A huge hydrocele in the occipital region was discovered in prenatal ultrasonography. After birth, CM III was diagnosed based on the hydrocele and cerebellar prolapse into the occipital bony deficit observed by brain MRI (Fig. 1). Three months after birth, she underwent surgery to remove the hydrocele and skin flap over the herniated cerebellar area. One month post-surgery, hydrocephalus developed, and a shunt was inserted.

At the time of visit to the department of rehabilitation medicine, the patient was 22 months old, could not raise her head, and had difficulty turning over and crawling (Table 1). On physical examination, a round, soft mass was discovered behind the neck and occiput (Fig. 2). Deep tendon reflex and reactive sensation of the hands and feet were preserved. On cranial examination, pupillary reflex and fundoscopic examination showed normal responses in both sides, but visual tracing of objects was uncertain (Hoyt level I) [5]. Due to very weak sucking reflex, drooling, and lack of a gag reflex, nutrition was supplied through a percutaneous endoscopic gastrostomy (PEG) tube. However, rough breathing or respiratory failure was not observed. In addition, the facial morpholo- gies were normal and no other combined congenital anomalies or hypertelorism were observed.

In the 2nd MRI examination, cerebellar prolapse into the occipital region and hydrocephalus were still observed. A videofluoroscopy swallowing study (VFSS) revealed a markedly delayed oral and pharyngeal transit time, and severe liquid aspiration during swallowing. A flash visual evoked potential (VEP) test was performed with goggles. Sweep speeds of $300 \mathrm{~ms}$ and a bandpass of 1-100 Hz were set, and each side was stimulated with $2 \mathrm{~Hz}$ for 100 times twice. A delay in P100 latency in both sides was observed [6], suggesting she had cortical visual impairment [7] (Table 2).

A rehabilitation program was applied for developmental delay, swallowing dysfunction, and cortical visual impairment. Using the concept of neurodevelopmental treatment, trunk balance control, and pelvic postural adjustment were performed for trunk ataxia due to the cerebellar lesion, and functional electrical stimulation of the lower cervicothoracic paravertebral muscles was repeatedly applied. Oromotor stimulations and head postural control programs for the swallowing difficulty were also applied.

For visual perception treatment, visual response training using a flashlight in a dark room was performed,

Table 1. Gross Motor Function Measure findings at 22 and 36 months of age

\begin{tabular}{lcc}
\hline \multicolumn{1}{c}{ Subject } & At 22 months (\%) & At 36 months (\%) \\
\hline Lying \& rolling & 49.0 & 78.4 \\
Sitting & 10.0 & 16.7 \\
Crawling & 0.0 & 4.8 \\
Standing & 0.0 & 0.0 \\
Walking & 0.0 & 0.0 \\
Total & 11.8 & 20.0 \\
\hline
\end{tabular}
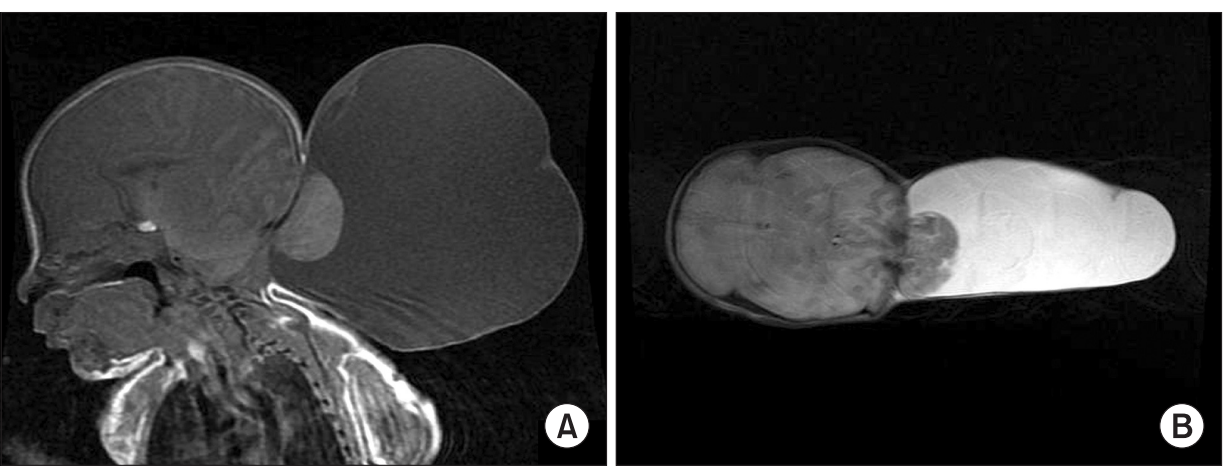

Fig. 1. (A) T1-weighted axial view and (B) T2-weighted sagittal view of brain magnetic resonance imaging at birth show a large sac with cerebellar herniation through the occipital area. 

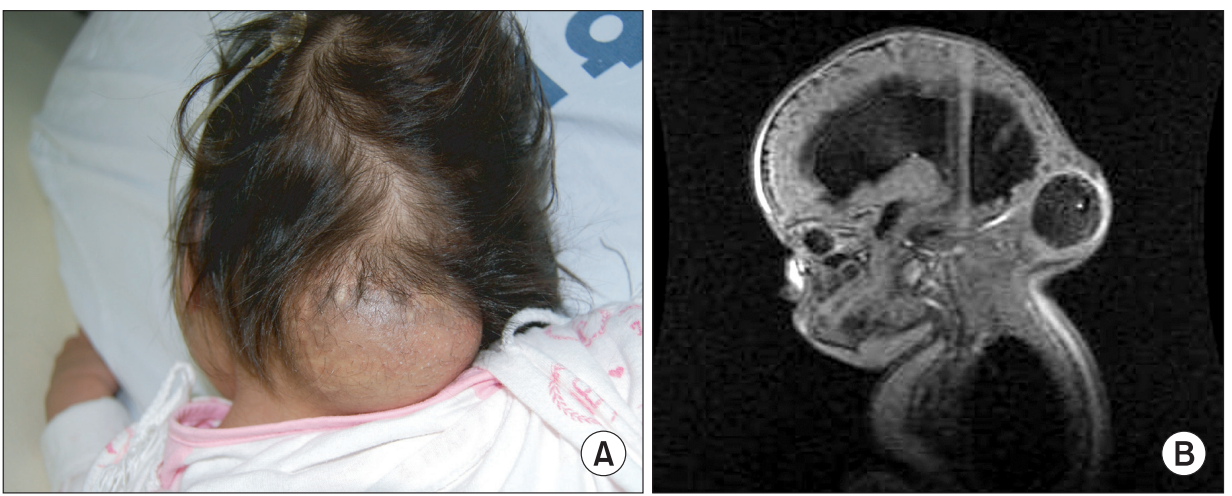

Fig. 2. (A) Photograph and (B) T1weighted sagittal view of brain magnetic resonance imaging at 22 months show meningocele at the craniocervical junction with hydrocephalus after removal of the hydrocele.

Table 2. Visual evoked potentials at 26 months and 36 months of age

\begin{tabular}{lcccr}
\hline & \multicolumn{2}{c}{ At 26 months } & \multicolumn{2}{c}{ At 36 months } \\
\cline { 2 - 5 } & Right & Left & Right & Left \\
\hline Latency $(\mathrm{ms})$ & $135.3^{\text {a) }}$ & $130.0^{\text {a) }}$ & $129.3^{\text {a) }}$ & 111.5 \\
Amplitude $(\mu \mathrm{V})$ & 1.0 & 1.5 & 0.8 & 1.7 \\
\hline
\end{tabular}

Reference values for latency are $103.4 \pm 19.9 \mathrm{~ms}$ at $1-2$ years and $104.1 \pm 22.6 \mathrm{~ms}$ at $2-4$ years, according to Laget et al. [6].

${ }^{\text {a) }}$ Abnormal findings.

applying the previously published treatment method of Malkowicz et al. [8]. The flashlight was reflected on both sides of the eyes at an interval of 5 seconds for about 1 minute, more than 10 times a day. This was performed 3 days a week for the first 6 months, and 2 days a week for the following 6 months (Fig. 3). From Hoyt level I, detecting only light perception before treatment, visual perception was improved to allow the ability to fix on colorful toys and follow moving colorful objects. Hoyt level was improved into the II-III level [5].

After 14 months with management, the 36-month-old child was improved to have the ability to roll over and crawl in the prone position, with partial head control (Table 1), and showed visual trace ability for light and sound stimulations. In the VEP test, the left side was normalized, while the right side showed decreased latency (Table 2). However, not much improvement in cognition was achieved, and the patient could still only blink at auditory stimulation, sometimes grabbing objects when held in her hand. In addition, poor swallowing and liquid aspiration were still observed in the follow-up VFSS after 1 year of treatment, and the PEG tube was still required for nutritional supply.

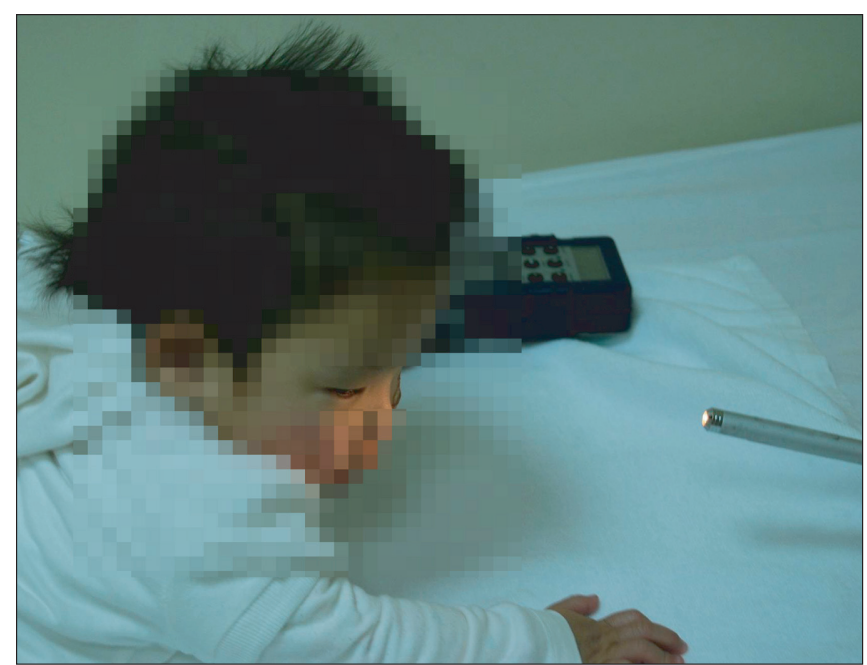

Fig. 3. Visual perception training with penlight for cortical visual impairment in progress.

\section{DISCUSSION}

The etiology of CM III is not precisely known, but researchers assume that the formation of the occipital area was imperfect due to incorrect neuralization during the ventricle extension process in the embryo, causing the subsequent prolapse of the cerebellum and the brainstem [9].

MRI examination is recommended for the diagnosis of CM III. It is also used for obtaining accurate anatomical information about the brain malformation, and detailed information of the venous sinus structure is very important in operation [10].

The first choice of treatment of meningoencephalocele in CM III patients is surgery, in order to prevent meningitis, or rupture of the encephalocele. A shunt operation for hydrocephalus is sometimes performed before the sac removal operation [10]. In any case, careful observation 
is necessary to determine whether hydrocephalus is present or not.

The rehabilitation methods for poor head control and trunk ataxia due to CM III are usually based on neurodevelopmental treatment. However, the concept of the treatment of cortical visual impairment in these cases seems to be unfamiliar.

The visual perception stimulation method was used to manage the cortical visual impairment. Malkowicz et al. [8] first introduced the concept based on the classification of Hoyt [5]. A flashlight was reflected in each eye in a dark and quiet room, and light detecting and contrast recognition training using a white/black board and penlight were continued. Meaningful improvement was reported in children treated with this method.

As mentioned above, CM III is a very rare congenital brain disease, for which the prognosis is known to be very poor. However, the survival rate has been increasing with the recent improvement of surgical techniques. This means that more infants with a severe form of $\mathrm{CM}$ are able to participate in rehabilitation treatment. We reported the rehabilitation treatment of a 36-month-old child with CM III after successful surgery to prevent central nervous system infection and expansion of ventricles. The improvement into a tolerable body condition after surgery, the infant's ability to grow well, and the use of intensive rehabilitation programs led to meaningful functional improvement. In the future, more attention must be paid to the rehabilitation issues concerning patients with CM III.

\section{CONFLICT OF INTEREST}

No potential conflict of interest relevant to this article was reported.

\section{ACKNOWLEDGMENTS}

This work was supported by Inha University Research Grant.

\section{REFERENCES}

1. Chiari H. Concerning alterations in the cerebellum resulting from cerebral hydrocephalus. Pediatr Neurosci 1987;13:3-8.

2. Cama A, Tortori-Donati P, Piatelli GL, Fondelli MP, Andreussi L. Chiari complex in children: neuroradiological diagnosis, neurosurgical treatment and proposal of a new classification (312 cases). Eur J Pediatr Surg 1995;5 Suppl 1:35-8.

3. Castillo M, Quencer RM, Dominguez R. Chiari III malformation: imaging features. AJNR Am J Neuroradiol 1992;13:107-13.

4. Cho EY, Lee JJ, Lim JW, Choen EJ, Ko KO, Lee YH. A case of Chiari III malformation. J Korean Child Neurol Soc 2005; 13:282-7.

5. Hoyt CS. Visual function in the brain-damaged child. Eye (Lond) 2003;17:369-84.

6. Laget P, Flores-Guevara R, D'Allest AM, Ostre C, Raimbault J, Mariani J. Maturation of visually evoked potentials in the normal child. Electroencephalogr Clin Neurophysiol 1977;43:732-44.

7. Dutton GN, Jacobson LK. Cerebral visual impairment in children. Semin Neonatol 2001;6:477-85.

8. Malkowicz DE, Myers G, Leisman G. Rehabilitation of cortical visual impairment in children. Int J Neurosci 2006;116:1015-33.

9. McLone DG, Knepper PA. The cause of Chiari II malformation: a unified theory. Pediatr Neurosci 1989;15:1-12.

10. Snyder WE Jr, Luerssen TG, Boaz JC, Kalsbeck JE. Chiari III malformation treated with CSF diversion and delayed surgical closure. Pediatr Neurosurg 1998;29:117-20. 